\title{
Green Route Fabrication of Graphene Oxide Reinforced Polymer Composites with Enhanced Mechanical Properties
}

\author{
R. Mahendran, ${ }^{1}$ D. Sridharan, ${ }^{1}$ K. Santhakumar, ${ }^{2}$ and G. Gnanasekaran ${ }^{3}$ \\ ${ }^{1}$ Department of Chemistry, Anjalai Ammal Mahalingam Engineering College, Anna University, Kovilvenni 614 403, India \\ ${ }^{2}$ School of Information and Communications and WCU Department of Nanobio Materials and Electronics, \\ Gwangju Institute of Science and Technology, Gwangju 500-712, Republic of Korea \\ ${ }^{3}$ Department of Agricultural Biotechnology, Research Institute for Agriculture and Life Sciences, Seoul National University, \\ Seoul 151921, Republic of Korea \\ Correspondence should be addressed to R. Mahendran; anishmahendran10@gmail.com
}

Received 26 March 2016; Accepted 26 May 2016

Academic Editor: Ana Benito

Copyright (c) 2016 R. Mahendran et al. This is an open access article distributed under the Creative Commons Attribution License, which permits unrestricted use, distribution, and reproduction in any medium, provided the original work is properly cited.

\begin{abstract}
A facile and "Green" route has been applied to fabricate graphene oxide (GO) reinforced polymer composites utilizing "deionized water" as solvent. The GO was reinforced into water soluble poly(vinyl alcohol) (PVA) and poly-2-acrylamido-2-methyl-1propanesulfonic acid (PAMPS) matrix by ultrasonication followed by mechanical stirring. The incorporation and dispersion of the GO in the polymer matrix were analyzed by XRD, FE-SEM, AFM, FT-IR, and TGA. Further, the FE-SEM and AFM images revealed that the surface roughness and agglomeration of the GO in the polymer matrix increased by increasing its concentration. Ionic exchange capacity, proton conductivity, and tensile texture results showed that the reinforcement of GO in the polymer matrix enhances the physicochemical properties of the host polymer. These PVA/PAMPS/GO nanocomposites showed improved mechanical stability compared to the pristine polymer, because of strong interfacial interactions within the components and homogeneous dispersion of the GO sheets in the PVA/PAMPS matrix.
\end{abstract}

\section{Introduction}

Reinforcement of nanofillers into the polymer matrix is being used to enhance the physicochemical properties of the host polymer. For the improvement of polymer stability, carbonaceous nanoparticles such as graphene, fullerenes, carbon nanotubes, and carbon nanofibers have been widely utilized by reinforcement into the polymer matrix [1-4]. Recently, graphene based nanofillers have been applied in fuel cells, electrochromic devices, lithium-ion batteries, conducting electrodes, ultracapacitors, solar cells, and chemical sensors, due to their electronic structure, thermomechanical properties, and homogeneous dispersion in the host polymers. The graphene oxide (GO) is a $2 \mathrm{D}$ sheet of covalently bonded carbon atoms consisting of hydroxyl, epoxide, and carbonyl functional groups on edges and basal planes, and these groups make the GO strongly hydrophilic and disperse in water quickly as individual sheets. However, the GOs are in powdery form and possess less mechanical stability, which protects their practical applications. In order to utilize this valuable material practically, it should be reinforced with polymeric materials to enhance their practical applications as well as physicochemomechanical properties of the host materials.

Chemically cross-linked poly(vinyl alcohol) and poly-2acrylamido-2-methyl-1-propane sulfonic acid (PVA-PAMPS) films have been widely attracted in fuel cells and electrochromic and electromechanical devices, due to their excellent proton conductivity, ease of preparation, biocompatibility, and cost-effectiveness [5-7]. The PAMPS is a sulfonic acid acrylic monomer, has high proton conductivity, and is hydrated due to sulfonic acid groups in its backbone. The PAMPS based materials are being effectively utilized in medical devices, adhesives, fuel cells, actuators, and so forth [7]. 
However, their major drawback is less mechanical stability and higher solubility in water. In order to overcome this drawback, the PAMPS has been blended with polymers for obtaining mechanically stable material. Specifically, PVA was blended with the PAMPS for obtaining flexible, mechanical, and thermally stable material [7]. Further, the PVA has been used in making artificial tears, tablet coating, drug delivery, and tissue replacement due to the characteristics of toxicologically safe, good oxygen permeability and biodegradability [8]. Very recently, graphene/graphene oxide was reinforced into PVA matrix, and the effect of the nanoparticle on the physical properties of the composites has been studied [9-17].

In the present study, a "Green route" was applied for the reinforcement of GO into the PVA/PAMPS matrix by solution blending. The primary function of the GO is improving the thermomechanical properties and dimensional stabilities and optimizing swelling ratio of the PVA/PAMPS polymer. Mechanical and thermal stabilities of the PVA/PAMPS/GO nanocomposites were studied through $\mathrm{X}$-ray diffraction (XRD), thermogravimetric analysis (TGA), ionic exchange capacity (IEC), proton conductivity, water uptake ratio, and tensile measurements. The reinforcing effect of the GO on the microstructural property in terms of surface roughness and agglomeration in the PVA/PAMPS matrix was investigated by Field Emission Scanning Electron Microscopy (FE-SEM) and Atomic Force Microscopy (AFM).

\section{Experimental Section}

2.1. Materials. Poly(vinyl alcohol) $(\mathrm{Mw}=61,000)$ and poly-2-acrylamido-2-methyl-1-propanesulfonic acid ( $\mathrm{Mw}=$ 2,000,000) were purchased from Aldrich, India. Graphene oxide was prepared via a modified Hummer method $[18,19]$ from graphite flakes. Distilled water was used to fabricate the composite films.

\subsection{Preparation of PVA/PAMPS/GO Films. PVA/PAMPS/GO} films are prepared by a solution-cast method. Figure 1 shows the molecular structures of the materials utilized for fabricating PVA/PAMPS/GO composites. Firstly, the PVA solution was prepared using deionized water as solvent and then heated to $80^{\circ} \mathrm{C}$ with continuous stirring until obtaining a homogeneous and transparent solution. Consequently, the PAMPS aqueous solution was poured into the PVA solution and stirred for 3 hours in order to get homogeneous mixture. Finally, the GO powder was dispersed in deionized water by ultrasonication for $10 \mathrm{~min}$ and the GO solution was added to the PVA/PAMPS mixture and stirred for 5 hours to get homogeneous mixture. PVA/PAMPS/GO samples were prepared with the weight ratio of $10: 10: 0.1$ and $10: 10: 0.5$ (Table 1). Further, the pristine PVA/PAMPS composite was prepared with the weight ratio of $10: 10$ in distilled water. The mixture was continuously stirred for 18 hours at $80^{\circ} \mathrm{C}$ until it becomes homogeneous and transparent. After removing bubbles under vacuum, the solution was poured in a Petri dish and dried in a vacuum oven at $60^{\circ} \mathrm{C}$ for 24 hours. Finally, the films were annealed at $100^{\circ} \mathrm{C}$ in an oven for about 24 hours to get physically cross-linked films.
2.3. Characterizations. Structural analysis of the PVA/ PAMPS/GO was carried out by Fourier Transform Infrared Spectroscopy (FT-IR, SHIMADZU, IR Prestige-21). Thermal stability of the PVA/PAMPS/GO composites was analyzed by thermogravimetric analysis (TGA/SDTA851e, Mettler Toledo) under nitrogen atmosphere with the heating rate of $10^{\circ} \mathrm{C} / \mathrm{min}$. The hydrophilic nature of the PVA/PAMPS/GO films was measured by a water uptake measurement at room temperature, and their ionic exchange capacity (IEC) is defined as the milliequivalent of sulfonic acid groups per gram of the sample by a conventional titration method $[20,21]$. Firstly, the dried polymeric film was weighed and immersed in $2.0 \mathrm{M} \mathrm{HCl}$ solution for 5-6 hours to protonize the sulfonic groups and then washed with deionized water until getting neutral $\mathrm{pH}$. Then, the film was immersed in a saturated $\mathrm{NaCl}$ solution for 12 hours to replace the protons of sulfonic acid groups with sodium ions. The replaced protons in the solution were titrated against $0.01 \mathrm{M} \mathrm{NaOH}$ solution using phenolphthalein as indicator [22]. The number of moles of the protons is equal to the moles of sulfonic groups in the PAMPS and the IEC is calculated from the titration data.

The X-ray diffraction of the nanocomposites was measured using DMAX-Ultima III X-ray diffractometer in the range of $2^{\circ}-90^{\circ}$. The $\mathrm{X}$-ray scattering intensity was experimentally determined as a function of the scattering vector " $q$ " whose modulus is defined as $q=(4 \pi / \lambda) \sin 2 \theta$, where $2 \theta$ is the scattering angle. The hydrophilic nature of the films was measured using water uptake $\left(w_{u}\right)$ that was calculated from the weight ratio of the wet film and dry film. Firstly, the dried sample is weighed and immersed in distilled water until reaching fully swelled state to obtain a well-hydrated film. The water uptake ratio of the film is calculated by the following equation:

$$
w_{u}(\%)=\frac{w_{w}-w_{d}}{w_{d}} \times 100,
$$

where $w_{d}$ is the weight of the dry film and $w_{w}$ is the weight of the water-swollen film.

The cross-sectional morphology of the PVA/PAMPS and PVA/PAMPS/GO films was analyzed using Field Emission Scanning Electron Microscopy (FE-SEM, Hitachi, S-4700). Images from the frozen-fractured cross section of the samples were obtained. The SEM image was analyzed using ImageProPlus software for particle size measurement. Tensile testing was performed using Universal Testing Machine (PT-200N, Minebea, Japan) according to the ASTM D882 standards. The tensile tests are conducted with PVA/PAMPS and PVA/PAMPS/GO composite specimens under the test speed of $10 \mathrm{~mm} / \mathrm{min}$.

2.4. Morphological Analysis by FE-SEM and AFM. The crosssectional morphology of the films was observed by Field Emission Scanning Electron Microscopy (FE-SEM) (Hitachi, S-4700). The dried films were fractured and mounted on a stub and then sputter-coated with gold. The surface roughness and agglomeration of the GO particles in the PVA/PAMPS matrix were identified by Atomic Force 


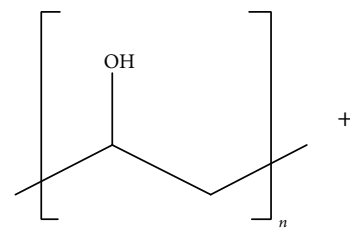

Poly(vinyl alcohol)

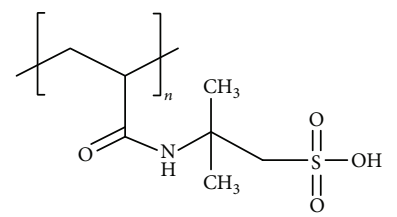

Poly-2-acrylamido-2methyl-1-propane sulfonic acid

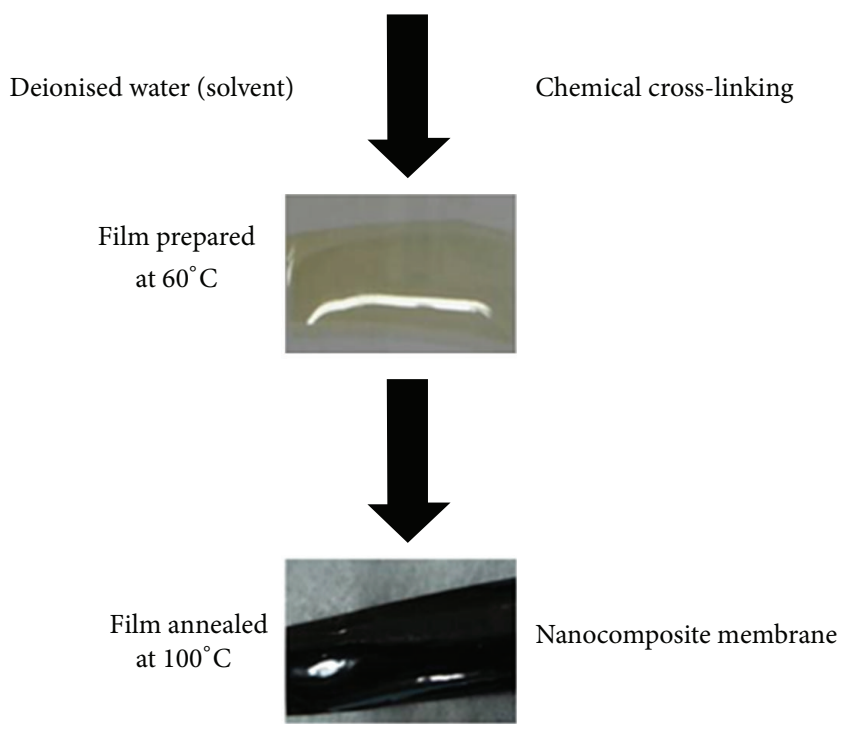

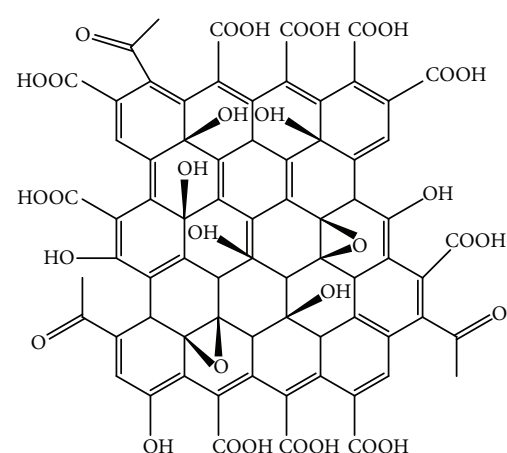

Graphene oxide

Figure 1: Preparation of cross-linked PVA/PAMPS/GO film.

TABLE 1: Physicochemical properties of PVA/PAMPS and PVA/PAMPS/GO (1-2) nanocomposites.

\begin{tabular}{lcccccc}
\hline Film code & PVA $(w t \%)$ & PAMPS $(w t \%)$ & GO $(w t \%)$ & Water uptake $(\%)$ & IEC $(\mathrm{meq} / \mathrm{g})$ & Thickness $(\mu \mathrm{m})$ \\
\hline PVA/PAMPS & 10 & 10 & 0 & 66.06 & 0.173 & 204 \\
PVA/PAMPS/GO-1 & 10 & 10 & 0.1 & 68.58 & 0.310 & 189 \\
PVA/PAMPS/GO-2 & 10 & 10 & 0.5 & 70.13 & 0.689 & 193 \\
\hline
\end{tabular}

Microscopy (AFM) (Digital Instruments, nanoscope III model).

\section{Results and Discussion}

The reaction scheme of the preparation of PVA/PAMPS/GO composites is depicted in Figure 1. The FT-IR spectrum of PVA, PAMPS, GO, and PVA/PAMPS/GO composite is shown in Figure 2. In PVA spectra, large bands between 3400 and $3000 \mathrm{~cm}^{-1}$ are linked to the stretching $\mathrm{O}-\mathrm{H}$ vibration of intermolecular and intramolecular hydrogen bonds, and the band in between 2900 and $2700 \mathrm{~cm}^{-1}$ refers to the stretching C-H of alkyl groups [23]. In the PAMPS spectra, the characteristics bands around 1556 and $1650 \mathrm{~cm}^{-1}$ clearly indicated the vibrational mode of amide groups, and the two sharp peaks at 1039 and $1221 \mathrm{~cm}^{-1}$ were also clearly observed for the S-O stretching of sulfonate groups, and the bands around $3350-3000 \mathrm{~cm}^{-1}$ are linked to the $\mathrm{O}-\mathrm{H}$ stretching vibration [23]. The GO shows its characteristic peaks around $3450 \mathrm{~cm}^{-1}$ for $\mathrm{O}-\mathrm{H}$ stretching vibrations, at $720 \mathrm{~cm}^{-1}$ for $\mathrm{C}=\mathrm{O}$ stretching vibrations, at $1250 \mathrm{~cm}^{-1}$ for $\mathrm{C}$ $\mathrm{OH}$ stretching vibrations, and at $1050 \mathrm{~cm}^{-1}$ for $\mathrm{C}-\mathrm{O}$ stretching vibrations [24]. Finally, in the spectra of PVA/PAMPS/GO composite, the signals around $1700 \mathrm{~cm}^{-1}$ are observed due 


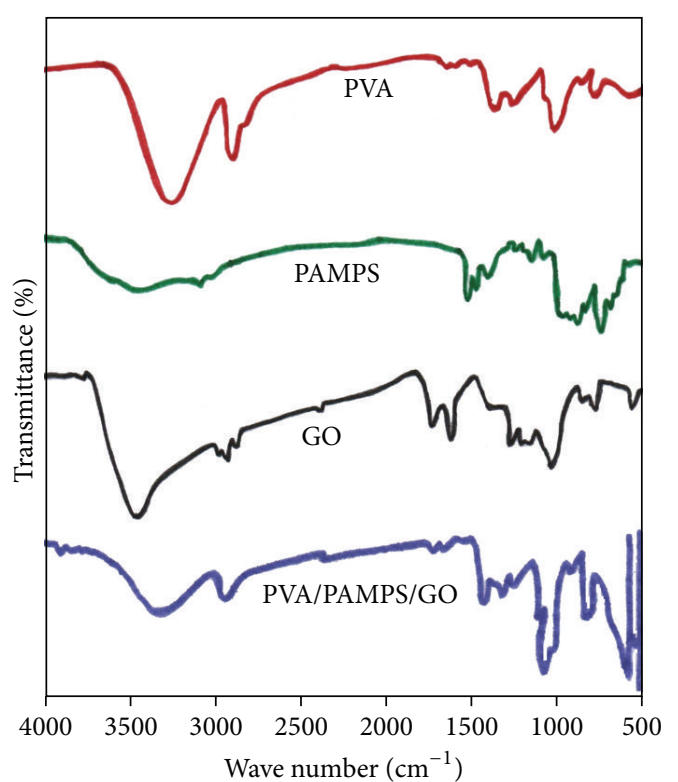

FIgure 2: FT-IR spectra of PVA, PAMPS, GO, and PVA/PAMPS/ GO-2 nanocomposite.

to the vibrational mode of amide groups $(\mathrm{C}=\mathrm{O}$ and $\mathrm{N}-\mathrm{H})$ of PAMPS, and the sharp peak at $1100 \mathrm{~cm}^{-1}$ belongs to the asymmetric $\mathrm{S}-\mathrm{O}$ stretching of sulfonate groups [23]. The peak around $1725 \mathrm{~cm}^{-1}$ related to $\mathrm{C}=\mathrm{O}$ (carbonyl and carboxyl) groups of the GO. Furthermore, the stretching absorption band attributed to the C-N of PAMPS decreases with more cross-linking, followed by an increased sharp peak due to the $\mathrm{C}=\mathrm{O}$ from PAMPS [25]. Further, the stretching vibrations from $\mathrm{C}=\mathrm{O}$ were observed at $1720 \mathrm{~cm}^{-1}$ and the stretching vibrations of $\mathrm{C}-\mathrm{O}$ groups were observed at $1060 \mathrm{~cm}^{-1}$. The peak observed around $3400 \mathrm{~cm}^{-1}$ was due to the $\mathrm{O}-\mathrm{H}$ stretching vibration of the GO, PAMPS, and PVA. In addition, the spectra illustrate the presence of $\mathrm{C}-\mathrm{O}\left(\nu_{\mathrm{C}-\mathrm{O}}\right.$ at $\left.1060 \mathrm{~cm}^{-1}\right)$, $\mathrm{C}-\mathrm{O}-\mathrm{C}\left(\nu_{\mathrm{C}-\mathrm{O}-\mathrm{C}}\right.$ at $\left.1250 \mathrm{~cm}^{-1}\right)$, and C-OH $\left(v_{\mathrm{C}-\mathrm{OH}} 1365 \mathrm{~cm}^{-1}\right)$ groups in the PVA, PAMPS, and GO [26].

Figure 3 shows the TGA spectrum of PVA, PAMPS, GO, and PVA/PAMPS/GO-2 composite. The sample was dried in a vacuum at $60^{\circ} \mathrm{C}$ for $15 \mathrm{~min}$ prior to the analysis. In the PVA spectrum, two major mass losses were identified. The first weight loss around $100-150^{\circ} \mathrm{C}$ due to moisture loss and the second weight loss around $250-350^{\circ} \mathrm{C}$ correspond to the thermal degradation of PVA [27]. In the TGA curve of GO, two major mass losses at about $100^{\circ} \mathrm{C}$ and $200-250^{\circ} \mathrm{C}$ were observed. At $100^{\circ} \mathrm{C}$, they could be attributed to the evaporation of water trapped between hydrophilic GO sheets. The mass loss around $200-250^{\circ} \mathrm{C}$ corresponds to the thermal decomposition of oxygen-containing functional groups from the GO surface. In the PAMPS, the decomposition temperature occurred at $100^{\circ} \mathrm{C}$ due to moisture loss, and around $300^{\circ} \mathrm{C}$ was the decomposition of sulfonate and propenyl groups. Finally, around $380-430^{\circ} \mathrm{C}$ was the degradation of main chain of the PAMPS [28]. In the degradation curve of PVA/PAMPS/GO composite, the sample was stable up to $170^{\circ} \mathrm{C}$, and three mass loss stages were detected. The first mass

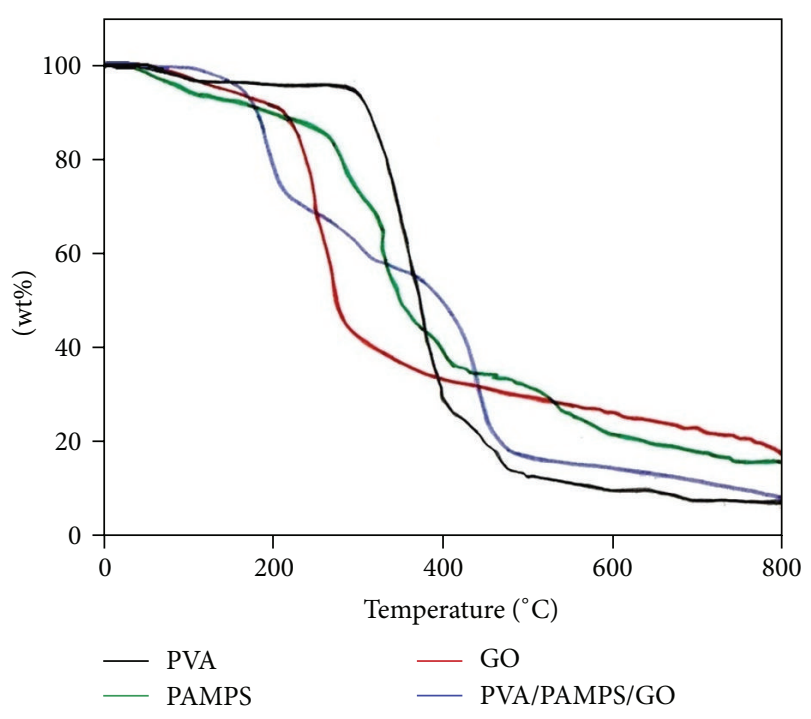

Figure 3: TGA spectrum of PVA, PAMPS, GO, and PVA/PAMPS/ GO-2 nanocomposite.

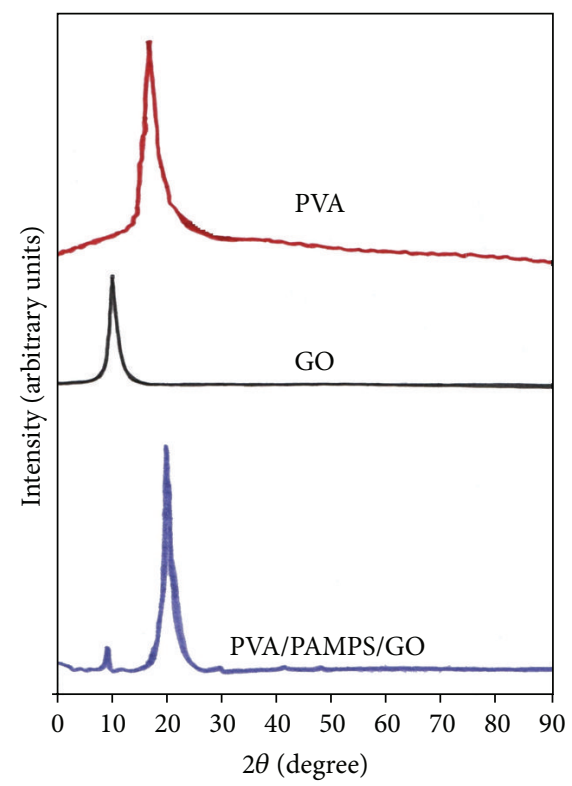

FIGURE 4: XRD patterns of PVA, GO, and PVA/PAMPS/GO nanocomposite.

loss $(28 \%)$ occurred at around $170-200^{\circ} \mathrm{C}$; the temperature is similar to the first mass loss of graphene oxide in air [29], which means that the first mass loss of PVA/PAMPS/GO may be attributed to the removal of labile oxygen functional groups from the GO. The second mass loss between $200^{\circ} \mathrm{C}$ and $400^{\circ} \mathrm{C}$ is due to the decomposition of sulfonic acid groups and the breaking of the PVA main chain, and the third mass loss $(56 \%)$ after $400^{\circ} \mathrm{C}$ is due to the breaking of the main chain and decomposition of the polymer backbone.

The XRD pattern of PVA, GO, and PVA/PAMPS/GO composite is plotted in Figure 4. In the PVA pattern, a broad peak around $2 \theta=20.3^{\circ}$ corresponds to the semicrystalline 


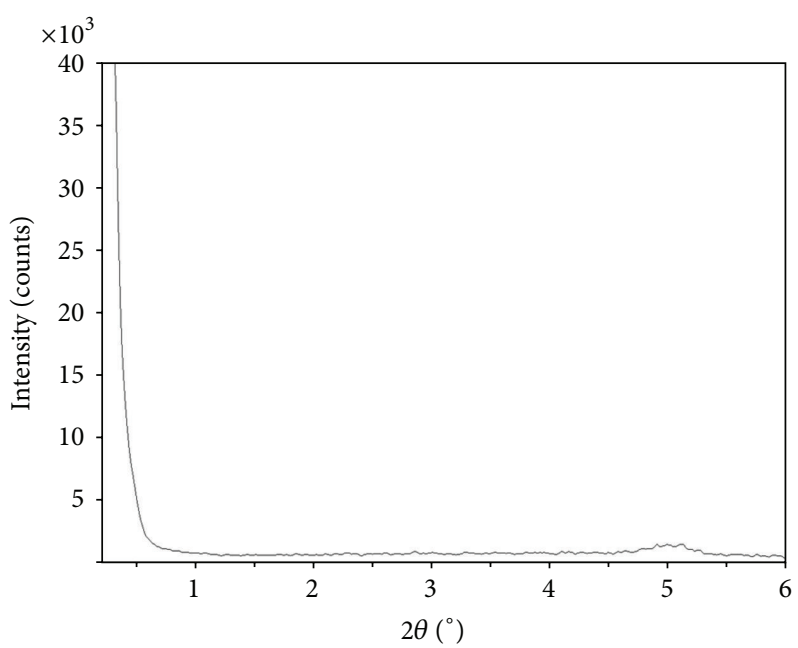

FIGURE 5: SAXS pattern of PVA/PAMPS/GO-2 film under hydrated condition.

nature of pristine PVA [30]. The diffraction peak around $2 \theta=10.5^{\circ}$ is very typical peak for the graphene oxide. The crystalline peak of GO was reported at around $2 \theta=9.8^{\circ}$, corresponding to a $d$-spacing of $0.77 \mathrm{~nm}$. However, as shown in Figure 4, the XRD peak of PVA/PAMPS/GO sheet appeared at $2 \theta=20^{\circ}$ and the similar results were also observed for PVA/GO composites [9]. This implies that the addition of PAMPS to the PVA/GO composites did not significantly change the crystalline nature of the PVA. In addition, the small peak of the GO in the PVA/PAMPS/GO composite indicates that the GO sheets were significantly exfoliated and uniformly dispersed in the polymer matrix.

The PVA/PAMPS/GO film's nanometer scale morphology was examined with the small-angle X-ray scattering (SAXS). The SAXS results of the film show a single peak at $2 \theta=5^{\circ}$ (Figure 8), which corresponds to a scattering vector $q=$ $0.548 \mathrm{~nm}^{-1}$ assuming that the wave length of X-ray is $1 \mathrm{~nm}$. Such trend can be explained by the semicrystalline nature of the PVA/PAMPS/GO composite. According to the SAXS study of PVA based composites, their peaks were obtained at similar scattering vectors [31]. To estimate average distance between domains, $d=2 \pi / q$ can be applied. From this equation, the average size of the nanocrystallites of the PVA/PAMPS/GO is calculated as $11.5 \mathrm{~nm}$ and it is still close to the range of the PVA crystals. This similarity is attributed to the semicrystalline domains in PVA and its composites. Both PVA and PVA/PAMPS/GO have single peak on SAXS spectrum, but composite has more broadening $q$ vector peak than pristine PVA, and the packing capacity also slightly increased. This change could be explained by lamellae packing as well as crystallinity from modified PVA [32].

Water content in the polymer matrix is an essential parameter to the mechanical properties of the polymers. The addition of GO did not change water uptake of the nanocomposite significantly (Table 1). This can be explained by the interaction between the GO and the polymer matrix [9]. A small amount of GO can improve the barrier property of polymer to water or can increase the cross-linking action within the polymer molecules. Hence, the incorporation of GO reduces the water permeability of the nanocomposite and leads to a less water uptake, which shows a consistency to the increase of Young's modulus of the nanocomposite.

The cross-sectional morphologies of the PVA/PAMPS and PVA/PAMPS/GO samples are shown in Figure 3. In the PVA/PAMPS/GO-2, the layered structure of the GOs was detected (Figures 3(e) and 3(f)). In addition, from the AFM images it was revealed that the surface roughness of the films increased with respect to the concentration ( 0 to $0.5 \mathrm{wt} \%$ ) of the GO in the polymer matrix of PVA/ PAMPS, PVA/PAMPS/GO-1 (0.1 wt $\%$ ), and PVA/PAMPS/ GO-2 (0.5 wt $\%)$, which was clearly identified from Figures $4(\mathrm{a})-4(\mathrm{c})$.

However, the reinforcement of graphene into the PVA matrix had no significant change in crystallinity [27]. Thus, the increase of Young's modulus of PVA/PAMPS/GO (Figure 8) can be explained by the increase of the interfacial interactions between the GOs into the PVA/PAMPS matrix. From Figures 5(e) and 5(f), the large aspect ratio and the molecular-level dispersion of the GO in the polymer matrix act as a favorable effect on the enhancement of mechanical properties. The excellent dispersion and mechanical stability of the GO are also an important factor in the enhancement of mechanical properties. Comparing to the PVA/PAMPS composite, Young's modulus of PVA/PAMPS/GO-2 nanocomposite is enhanced up to four times, which is clearly identified from Figure 8. Further, the ionic exchange capacity (IEC) results indicated the presence of acidic functional groups in the PAMPS and GOs. In particular, the trapped PAMPS chains in the PVA matrix import the significant properties such as moderate swelling, good mechanical strength, flexibility, and high proton conductivity, because the PAMPS 


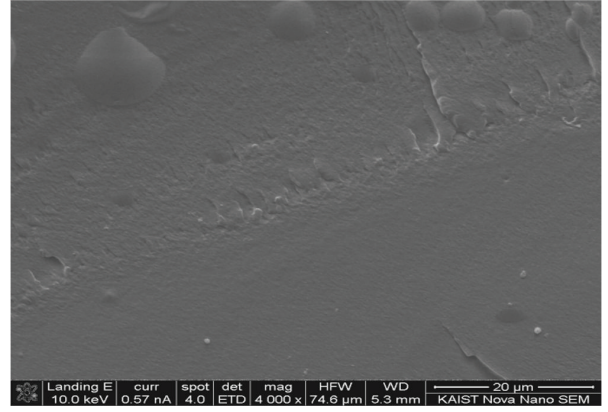

(a)

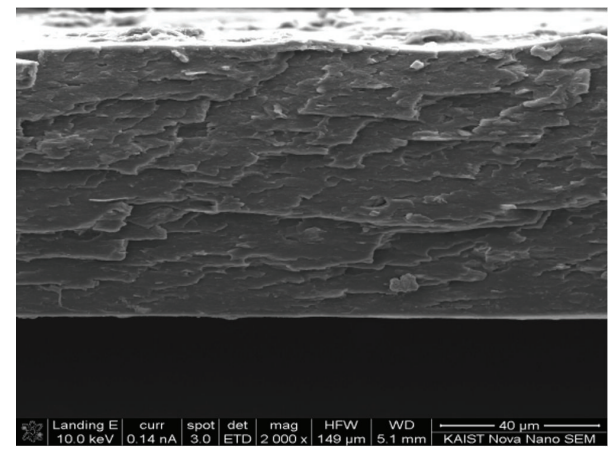

(c)

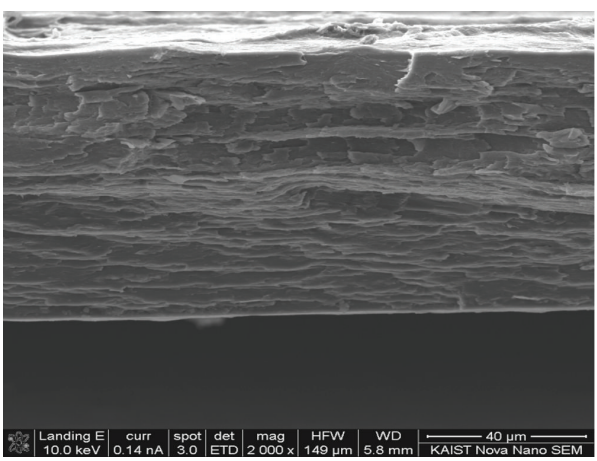

(e)

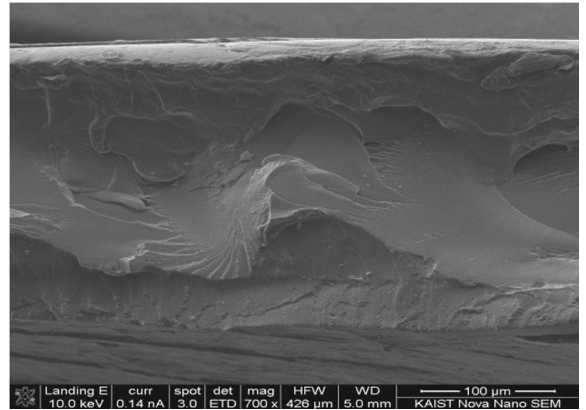

(b)

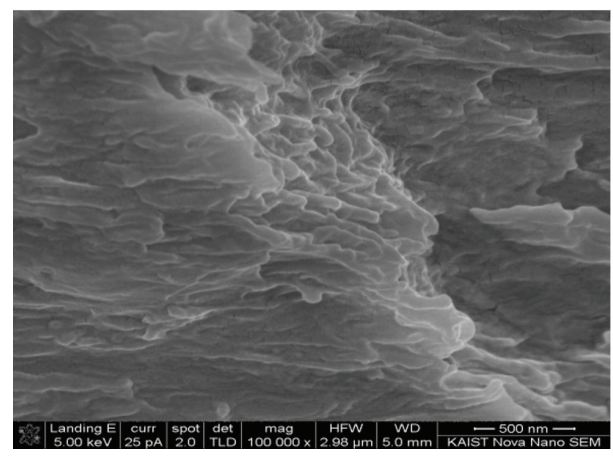

(d)

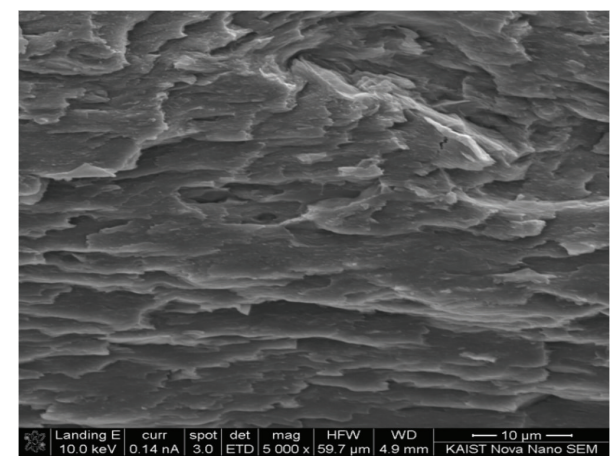

(f)

Figure 6: FE-SEM image of PVA/PAMPS ((a) and (b)), PVA/PAMPS/GO-1 ((c) and (d)), and PVA/PAMPS/GO-2 ((e) and (f)).

forms gels when cross-linked with the host functionalized polymer [28]. As shown in Table 1, both IEC and proton conductivity improved as the GO content increased in the polymer matrix, which is due to its high hydrophilicity and proton conductivity.

\section{Conclusion}

Graphene oxide reinforced poly(vinyl alcohol) and poly2-acrylamido-2-methyl-1-propanesulfonic acid based nanocomposites were developed utilizing the deionized water as solvent ("Green" method) by solution casting method. The characteristics of the cross-linking of the polymers and the GO in the composite were validated by FT-IR and TGA. Further, the exfoliation and alignment of the GOs in the polymer matrix were investigated by XRD. The FE-SEM and AFM images concluded the homogeneous dispersion of the GO particles on the surface and bulk of the films (Figures 6 and 7). Due to the barrier effect of GO in the polymer, the water uptake property of the PVA/PAMPS/GO nanocomposite did not change by increasing the GO contents. The ionic exchange capacity (IEC) and proton conductivity improved by loading GOs. Moreover, the PVA/PAMPS/GO-2 composite had four times enhanced Young's modulus compared to the pristine PVA/PAMPS by adding minute quantity of GO $(0.5 \mathrm{wt} \%)$ to the PVA/PAMPS matrix. 


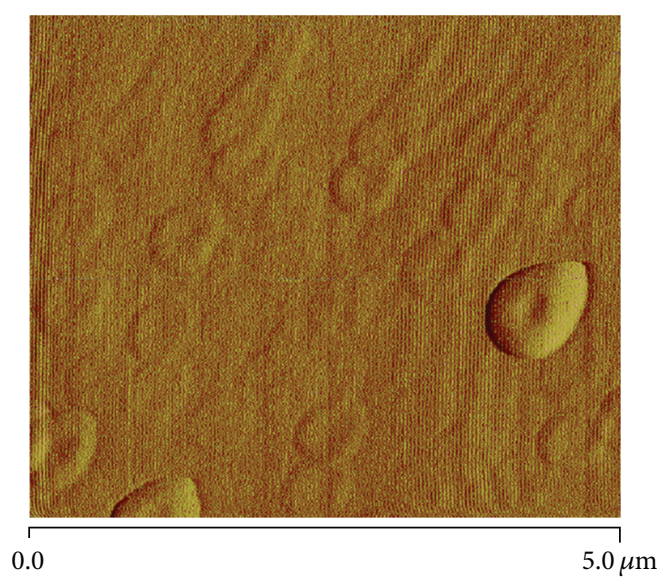

(a)

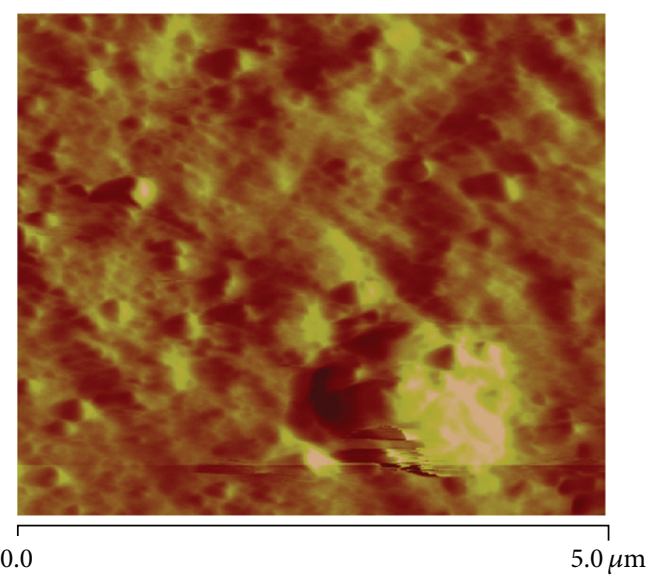

(b)

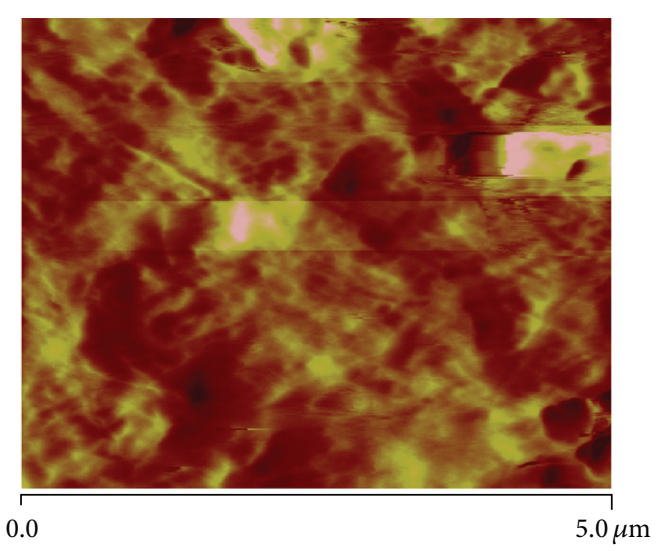

(c)

FIGURE 7: AFM tapping mode images of PVA/PAMPS (a), PVA/PAMPS/GO-1 (b), and PVA/PAMPS/GO-2 (c).

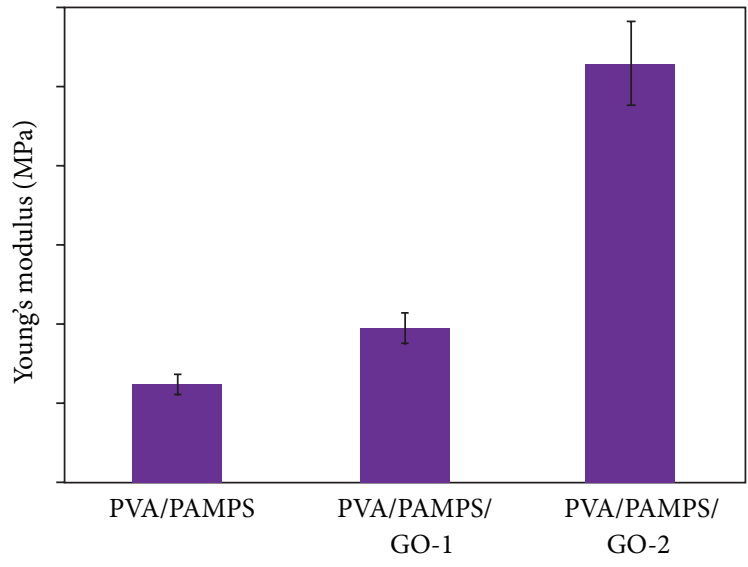

Figure 8: Young's modulus of PVA/PAMPS and PVA/PAMPS/GO (1-2) as a function of GO content.

\section{Competing Interests}

The authors declare that there are no competing interests regarding the publication of this paper.

\section{References}

[1] X. Xie, L. Qu, C. Zhou et al., "An asymmetrically surfacemodified graphene film electrochemical actuator," ACS Nano, vol. 4, no. 10, pp. 6050-6054, 2010.

[2] R. M. Zaid, F. C. Chong, E. Y. L. Teo, E.-P. Ng, and K. F. Chong, "Reduction of graphene oxide nanosheets by natural beta carotene and its potential use as supercapacitor electrode," Arabian Journal of Chemistry, vol. 8, no. 4, pp. 560-569, 2015.

[3] J. J. Fu, Z. Z. Shi, M. Li, Y. Wang, and L. Yu, "Labelfree detection of chondroitin sulphate proteoglycan 4 by a polyaniline/graphene nanocomposite functionalized impedimetric immunosensor," Journal of Nanomaterials, vol. 2016, Article ID 7834657, 8 pages, 2016.

[4] C. F. Matos, F. Galembeck, and A. J. G. Zarbin, "Multifunctional and environmentally friendly nanocomposites between natural rubber and graphene or graphene oxide," Carbon, vol. 78, pp. 469-479, 2014.

[5] C.-A. Dai, C.-J. Chang, A.-C. Kao et al., "Polymer actuator based on PVA/PAMPS ionic membrane: optimization of ionic transport properties," Sensors and Actuators A: Physical, vol. 155, no. 1, pp. 152-162, 2009.

[6] J. Qiao, T. Hamaya, and T. Okada, "Chemically modified poly(vinyl alcohol)-poly(2-acrylamido-2-methyl-1-propanes- 
ulfonic acid) as a novel proton-conducting fuel cell membrane," Chemistry of Materials, vol. 17, no. 9, pp. 2413-2421, 2005.

[7] J. Qiao, T. Okada, and H. Ono, "High molecular weight PVAmodified PVA/PAMPS proton-conducting membranes with increased stability and their application in DMFCs," Solid State Ionics, vol. 180, no. 23-25, pp. 1318-1323, 2009.

[8] E. A. Kamoun, E.-R. S. Kenawy, T. M. Tamer, M. A. El-Meligy, and M. S. Mohy Eldin, "Poly (vinyl alcohol)-alginate physically crosslinked hydrogel membranes for wound dressing applications: characterization and bio-evaluation," Arabian Journal of Chemistry, vol. 8, no. 1, pp. 38-47, 2015.

[9] J. Wang, X. Wang, C. Xu, M. Zhang, and X. Shang, "Preparation of graphene/poly(vinyl alcohol) nanocomposites with enhanced mechanical properties and water resistance," Polymer International, vol. 60, no. 5, pp. 816-822, 2011.

[10] L. Zhang, Z. Wang, C. Xu et al., "High strength graphene oxide/polyvinyl alcohol composite hydrogels," Journal of Materials Chemistry, vol. 21, no. 28, pp. 10399-10406, 2011.

[11] T. Abdul kareem and A. Anu kaliani, "Synthesis and thermal study of octahedral silver nano-plates in polyvinyl alcohol (PVA)," Arabian Journal of Chemistry, vol. 4, no. 3, pp. 325-331, 2011.

[12] B. Wang, Z. Chen, J. Zhang et al., "Fabrication of PVA/graphene oxide/ $/ \mathrm{TiO}_{2}$ composite nanofibers through electrospinning and interface sol-gel reaction: effect of graphene oxide on PVA nanofibers and growth of $\mathrm{TiO}_{2}$," Colloids and Surfaces A, vol. 457, no. 1, pp. 318-325, 2014.

[13] N. Wang, P. R. Chang, P. Zheng, and X. Ma, "Graphenepoly(vinyl alcohol) composites: fabrication, adsorption and electrochemical properties," Applied Surface Science, vol. 314, pp. 815-821, 2014.

[14] C. Bao, Y. Guo, L. Song, and Y. Hu, "Poly(vinyl alcohol) nanocomposites based on graphene and graphite oxide: a comparative investigation of property and mechanism," Journal of Materials Chemistry, vol. 21, no. 36, pp. 13942-13950, 2011.

[15] L. Jiang, X.-P. Shen, J.-L. Wu, and K.-C. Shen, "Preparation and characterization of graphene/poly(vinyl alcohol) nanocomposites," Journal of Applied Polymer Science, vol. 118, no. 1, pp. 275279, 2010.

[16] T. Zhou, F. Chen, C. Tang et al., "The preparation of high performance and conductive poly (vinyl alcohol)/graphene nanocomposite via reducing graphite oxide with sodium hydrosulfite," Composites Science and Technology, vol. 71, no. 9, pp. 1266-1270, 2011.

[17] M. Han, J. Yun, H.-I. Kim, and Y.-S. Lee, "Effect of surface modification of graphene oxide on photochemical stability of poly(vinyl alcohol)/graphene oxide composites," Journal of Industrial and Engineering Chemistry, vol. 18, no. 2, pp. 752-756, 2012.

[18] S. Park and R. S. Ruoff, "Chemical methods for the production of graphenes," Nature Nanotechnology, vol. 4, no. 4, pp. 217-224, 2009.

[19] D. Chen, H. Feng, and J. Li, "Graphene oxide: preparation, functionalization, and electrochemical applications," Chemical Reviews, vol. 112, no. 11, pp. 6027-6053, 2012.

[20] E. López-Chávez, Y. Peña-Castañeda, G. González-García, P. Perales-Enciso, A. García-Quiroz, and J. Irán Díaz-Góngora, "Theoretical methodology for calculating water uptake and ionic exchange capacity parameters of ionic exchange membranes with applications in fuel cells," International Journal of Hydrogen Energy, vol. 40, no. 48, pp. 17316-17322, 2015.
[21] J. Kerres, W. Cui, R. Disson, and W. Neubrand, "Development and characterization of cross linked ionomer films based upon sulfinated and sulfonated PSU crosslinked PSU blend films by disproportionation of sulfinic acid groups," Journal of Film Science, vol. 139, pp. 211-225, 1998.

[22] D. S. Kim, M. D. Guiver, S. Y. Nam et al., "Preparation of ion exchange membranes for fuel cell based on crosslinked poly(vinyl alcohol) with poly(styrene sulfonic acid-co-maleic acid)," Journal of Membrane Science, vol. 281, no. 1-2, pp. 156162, 2006.

[23] M. Erkartal, H. Usta, M. Citir, and U. Sen, "Proton conducting poly(vinyl alcohol) (PVA)/ poly(2-acrylamido-2-methylpropane sulfonic acid) (PAMPS)/ zeolitic imidazolate framework (ZIF) ternary composite membrane," Journal of Membrane Science, vol. 499, pp. 156-163, 2016.

[24] J. Song, X. Wang, and C.-T. Chang, "Preparation and characterization of graphene oxide," Journal of Nanomaterials, vol. 2014, Article ID 276143, 6 pages, 2014.

[25] S. Zhong, X. Cui, Y. Gao, W. Liu, and S. Dou, "Fabrication and properties of poly(vinyl alcohol)-based polymer electrolyte membranes for direct methanol fuel cell applications," International Journal of Hydrogen Energy, vol. 39, no. 31, pp. 1785717864, 2014.

[26] C. Xu, B. Xu, Y. Gu, Z. Xiong, J. Sun, and X. S. Zhao, "Graphenebased electrodes for electrochemical energy storage," Energy \& Environmental Science, vol. 6, no. 6, pp. 1388-1414, 2013.

[27] N. Shehata, N. Madi, M. Al-Maadeed, I. Hassounah, and A. Ashraf, "Improved electrical conductivity of carbon/polyvinyl alcohol electrospun nanofibers," Journal of Nanomaterials, vol. 2015, Article ID 812481, 5 pages, 2015.

[28] V. Azmeera, P. Adhikary, and S. Krishnamoorthi, "Synthesis and characterization of graft copolymer of dextran and 2-acrylamido-2-methylpropane sulphonic acid," International Journal of Carbohydrate Chemistry, vol. 2012, Article ID 209085, 7 pages, 2012.

[29] N. R. Wilson, P. A. Pandey, R. Beanland et al., "Graphene oxide: structural analysis and application as a highly transparent support for electron microscopy," ACS Nano, vol. 3, no. 9, pp. 2547-2556, 2009.

[30] N. Ahad, E. Saion, and E. Gharibshahi, "Structural, thermal, and electrical properties of Pva-sodium salicylate solid composite polymer electrolyte," Journal of Nanomaterials, vol. 2012, Article ID 857569, 8 pages, 2012.

[31] H. S. Mansur, R. L. Oréfice, and A. A. P. Mansur, "Characterization of poly(vinyl alcohol)/poly(ethylene glycol) hydrogels and PVA-derived hybrids by small-angle X-ray scattering and FTIR spectroscopy," Polymer, vol. 45, no. 21, pp. 7193-7202, 2004.

[32] J. Liang, Y. Huang, L. Zhang et al., "Molecular-level dispersion of graphene into poly(vinyl alcohol) and effective reinforcement of their nanocomposites," Advanced Functional Materials, vol. 19, no. 14, pp. 2297-2302, 2009. 

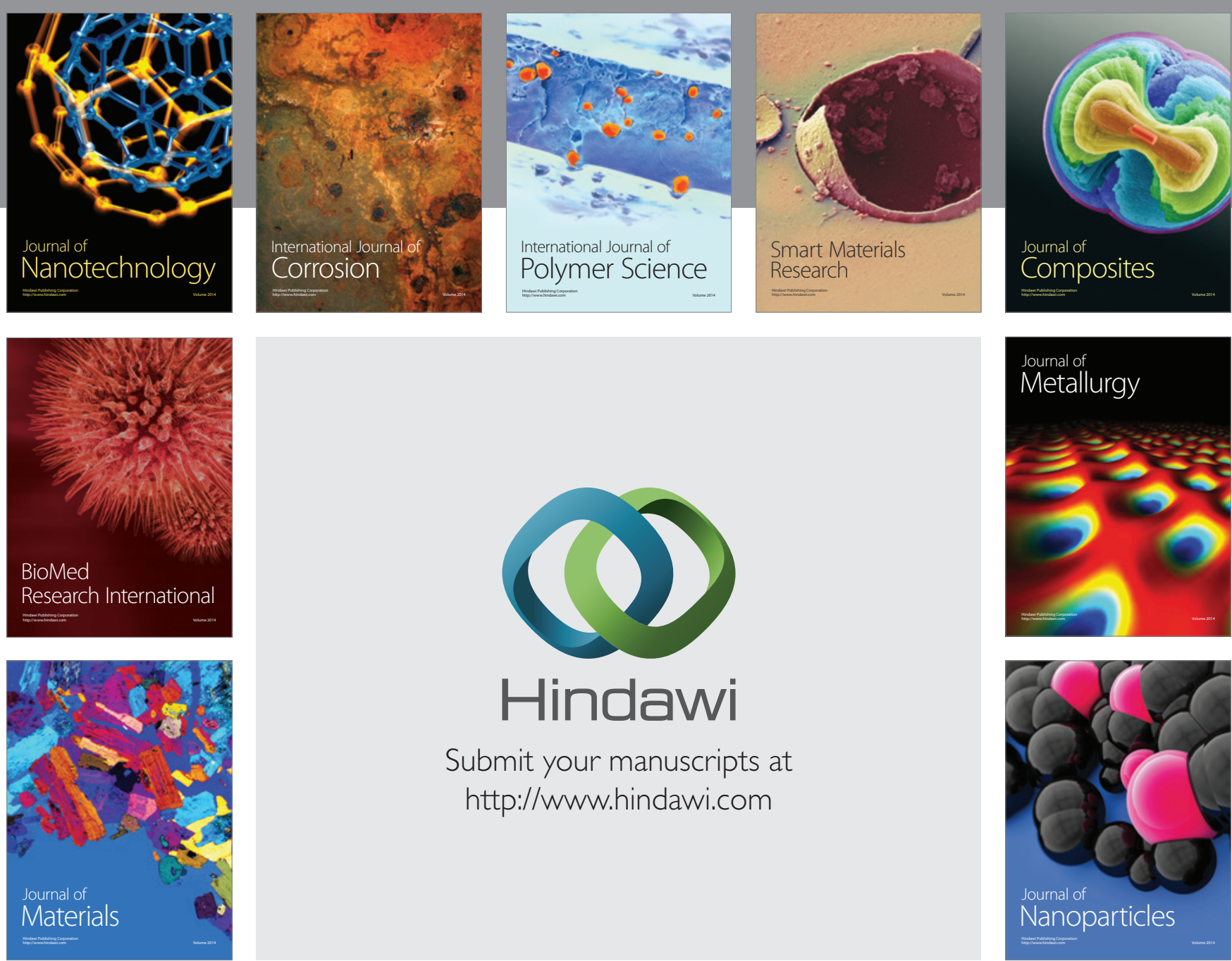

\section{Hindawi}

Submit your manuscripts at

http://www.hindawi.com

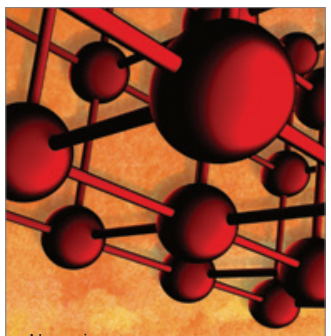

Materials Science and Engineering
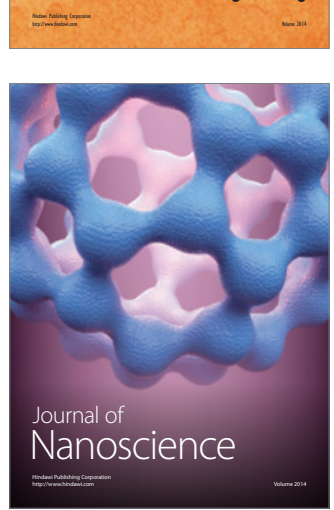
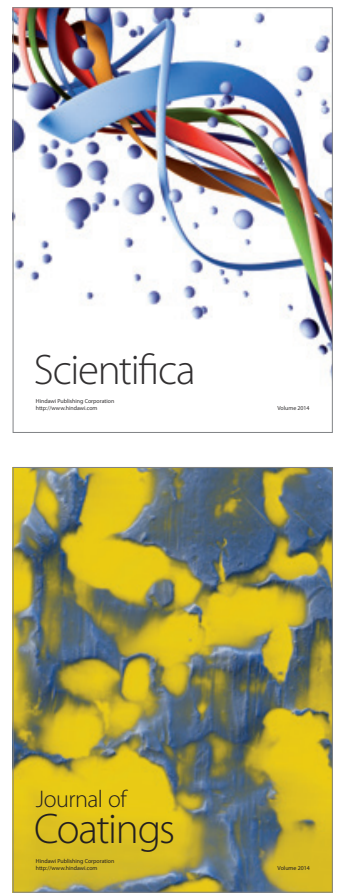
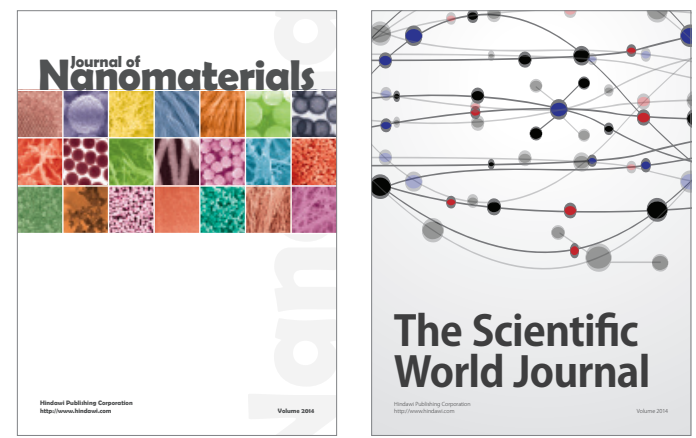

The Scientific World Journal
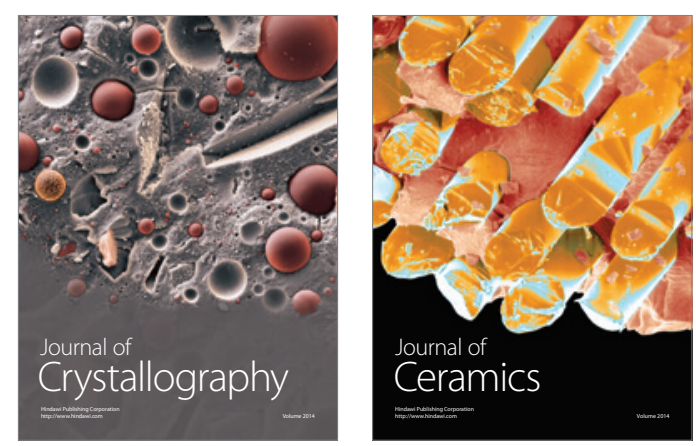
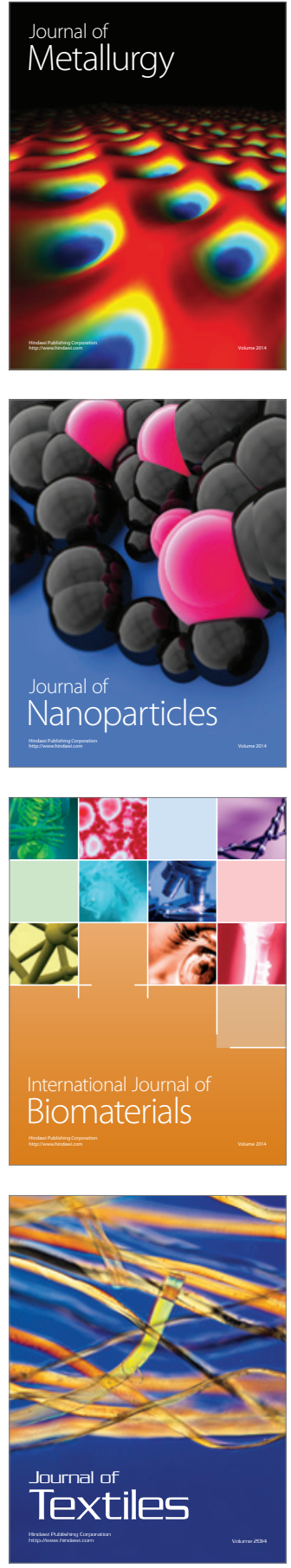